\title{
Connection for TESPA1 Polymorphisms to ankylosing spondylitis incidence in the Chinese Population
}

Hua-Wei Liu

Tsinghua University

Dai-Xu Wei

Northwest University

Da-Wei He

Tsinghua University

Jiu-Zheng Deng

Tsinghua University

Jian-Jin Zhu

Tsinghua University

Kai Xu

Tsinghua University

Dong Hu

Tsinghua University

Jing Li

Chinese PLA General Hospital

Wen-Hao Hu

Chinese PLA General Hospital

Yan-Wang

Chinese PLA General Hospital

Song-Hua Xiao ( $\nabla$ ncjskud@126.com )

Tsinghua University

Li-Gong Fu ( $\nabla$ snpxmir@yeah.net)

Tsinghua University https://orcid.org/0000-0001-5981-9713

Research article

Keywords: TESPA1; Ankylosing spondylitis; Polymorphism; PCR-RFLP

Posted Date: May 15th, 2020

DOI: https://doi.org/10.21203/rs.3.rs-28181/v1 
License: (c) (i) This work is licensed under a Creative Commons Attribution 4.0 International License. Read Full License 


\section{Abstract \\ Background}

The aim of this study was to investigate whether thymocyte-expressed, positive selection-associated 1 (TESPA1) gene polymorphisms were associated with increased risk of developing ankylosing spondylitis(AS) in a Chinese Han population.

\section{Methods}

A total of 99 AS patients were recruited as case group and 96 healthy individuals were collected as control group. TESPA1 polymorphisms were genotyped by polymerase chain reaction (PCR) and sequencing methods. The genotype distribution of TESPA1 gene rs 4758993 and rs 4758994 polymorphism was detected by Hardy-Weinberg equilibrium (HWE). The genotype and allele distributions of each polymorphism were also compared between groups. Moreover, odds ratios (OR) with $95 \%$ confidence intervals $(95 \% \mathrm{Cl})$ were calculated using the $\chi^{2}$ test to evaluate the association between AS susceptibility and TESPA1 polymorphisms.

\section{Results}

rs4758993 and rs4758994 polymorphisms were conformed to be in HWE in genotypes distribution of the control group ( $P>0.05$ for both). A remarkable decrease trend of rs4758993 AG genotype and A allele were detected in AS patients than in healthy controls ( $P=0.01$ and 0.02 , respectively), indicating that they obviously decreased the risk of $A S$ in a Chinese Han population $(\mathrm{OR}=0.303,95 \% \mathrm{Cl}=0.144-0.637 ; \mathrm{OR}=$ $0.002,95 \% \mathrm{Cl}=0.173-0.703)$. However, No significant differences were detected for TESPA1 gene rs4758994 polymorphism in both genotype and allele distributions between case and control groups ( $P>$ 0.05).

\section{Conclusions}

Our findings suggest that TESPA1 gene rs4758993 polymorphism was significantly associated with AS susceptibility in the Chinese Han population and the mutant A allele severed as a protect factor for the development of AS.

\section{Background}

Ankylosing spondylitis (AS) is the most common chronic inflammatory disorder of spondyloarthropathy $(\mathrm{SpA})$ involving the axial skeleton, sacroiliac joint, and periphery joints[1-3]. AS is generally characterised by sacroiliac joint and spine attachment point inflammation, which can cause spine fibrosis and poker spine, leading to damage of muscle, skeleton, and lung function $[4,5]$. The increasing prevalence of AS 
lead to heavy economic and social burdens for patients and their families in China. Growing evidence indicates that AS is caused by genetic and environmental factors. And genetic factors play the leading role in the onset of AS[6, 7]. Moreover, with the development of molecular biology and modern genetics many AS-associated genes have been discovered, such as pentraxin3 gene (PTX3), protein tyrosine phosphatase non-receptor type 22 (PTPN22) and IL-23R[8-10]. But these efforts fail to completely explain the etiology of AS, and more related factors need to be discovered.

TESPA1, a component of the T cell receptor (TCR) signalosome, is essential for T cell selection and maturation through the regulation of TCR signaling during T cell development demonstrated by the team of Wang D[11]. Another study reported that TESPA1 can as a novel binding partner of IP3R in the T and B lymphocytes, which shed light on the molecular mechanism underlying calcium signaling through the regulation of inositol 1, 4, 5-trisphosphate receptor (IP3R) in the immune system[12]. The IP3R is a calcium channel expressed on ER membranes, which also can be regulated by many intracellular modulators such as $\mathrm{Ca}^{2+}$, phospho rylation, and associated proteins [13-15]. These studies provide new evidence for mechanisms of TESPA1 gene related diseases in diagnosis and treatment. The study carried out by Wang $\mathrm{C}$ et al. reported that changes in the Th1/Th2 and Th17/Treg ratios are evidence for the suffering of AS[16]. In a recent study, Yao $Y$ et al. found that TESPA1 may be associated with $B$ cell function and the onset of rheumatoid arthritis(RA)[17]. Few studies have explored the exact function of TESPA1 in AS. Therefore, in this study our aim was to analyze whether TESPA1 gene polymorphisms are associated with risk of AS.

In the present study, we selected the common SNPs (rs4758993 and rs4758994) of TESPA1 to investigate their influence on AS development. And we explored the relationship between the genetic polymorphisms of the TESPA 1 gene and the risk of AS in Chinese Han population.

\section{Methods}

\section{Subjects}

In this study, a total of 99 patients (47 men, 42 women; mean age: $40.09 \pm 18.36$ years) with AS without other immune-related diseases were enrolled, along with 96 unrelated healthy volunteers without a family history of AS or other immune-related diseases, who were matched for age and gender. All subjects were all from Beijing Tsinghua Changgung Hospital, School of Clinical Medicine, Tsinghua University from March 2014 to March 2016 and they had no blood relation with other study subjects. We excluded patients with other immune or inflammatory diseases, tumors, or cardiovascular disease. The controls underwent physical examination in the same hospital.

This study was approved by the Research Ethics Committee of Beijing Tsinghua Changgung Hospital, School of Clinical Medicine, Tsinghua University and Informed consent was obtained from all of the patients. All individuals are from the Han Chinese population.

\section{Sample collecting}


$5 \mathrm{ml}$ fasting peripheral venous blood was collected from each subject using a blood collection tube. Blood samples were immediately centrifuged at $3000 \mathrm{rpm}$ for $10 \mathrm{~min}$, and the supernatant was kept at $-80^{\circ} \mathrm{C}$ for further analyses.

\section{DNA extraction and genotyping}

The genomic DNA was extracted by TaKaRa Genome DNA Extraction Kit (Dalian Biological Engineering CO., LTD, China), according to the manufacturer's instructions, and was stored at $-20^{\circ} \mathrm{C}$. Polymerase chain reaction (PCR) was conducted for genotyping of TESPA1 polymorphisms. The primer sequences for TESPA1 gene rs4758993 and rs4758994 polymorphisms were designed by Primer Premier 5.0 software, and were synthesized by Sangon Biothch (Shanghai, China) (Table 1). The PCR procedure was run according the following steps: $95^{\circ} \mathrm{C}$ pre-degeneration for $5 \mathrm{~min}, 30$ cycles of degeneration at $95^{\circ} \mathrm{C}$ for 30 $\mathrm{s}, 57^{\circ} \mathrm{C}$ annealing for $30 \mathrm{~s}, 72^{\circ} \mathrm{C}$ extension for $30 \mathrm{~s}$, and final extension at $72^{\circ} \mathrm{C}$ for $5 \mathrm{~min}$. Genotyping of TESPA1 gene rs 4758993 and rs 4758994 was completed by sequencing these PCR products using the genomic DNA as templates.

\section{Statistical analysis}

All data showed was conducted using PASW Statistics 18.0 statistical software. Hardy-Weinberg disequilibrium in controls was evaluated using the chi-square test based on 2 TESPA1 polymorphisms. Relative risk of AS based on TESPA1 polymorphism is represented with odds ratios (OR) and $95 \%$ confidence intervals $(95 \% \mathrm{Cl})$. The comparison among genotype and allele were measured by the $\chi^{2}$ test. The $P$ value less than 0.05 was considered as statistically significant.

\section{Results}

\section{HWE test}

The genotype distributions of both TESPA1 rs4758993 and rs4758994 polymorphisms in both case and control groups. The genotype distributions of each SNP all had non-significant $P$ values $(P>0.05)$, which showed that this study group was a representative Mendelian population.

\section{Distributions of TESPA1 gene polymorphisms between groups}

Genotype, allele frequencies of TESPA1 polymorphisms, and their effects on AS risk were shown in Table 2. The distribution of genotypes and alleles of rs 4758993 was significantly different between the case and control groups. Compared with control groups, the AG genotype frequency in the case was remarkable decreased $(31.25 \%$ VS $12.12 \% P=0.01)$ and it showed a significant association with the risk of $\mathrm{AS}(\mathrm{OR}=0.303,95 \% \mathrm{Cl}=0.144-0.637)$. However, the frequencies of rs $4758993 \mathrm{GG}$ and $\mathrm{AA}$ genotypes were respectively $87.88 \%, 0 \%$ in AS patients and $68.75 \%, 0 \%$ in controls respectively. Data showed that 
the $\mathrm{GG}$ and $\mathrm{AA}$ genotypes frequencies were no differences between groups $(P>0.05)$. Meanwhile, lower frequency of A allele was also found in case group compared with control groups (6.06\% vs $15.62 \%)$, and the results also indicated that the $A$ allele of rs4758993 could meaningfully decrease AS incidence $(O R=$ $0.348,95 \% \mathrm{Cl}=0.173-0.703, P=0.02$ ). All results suggested that $T E S P A 1$ gene rs 4758993 polymorphism was associated with AS susceptibility in the Chinese Han population, and the AG genotype and A allele were protect factor for the onset of AS. Frequencies of rs $4758994 \mathrm{GG}, \mathrm{GA}$ and AA genotypes were respectively $13.13 \%, 38.38 \%, 48.49 \%$ in AS patients and $12.5 \%, 33.33 \%, 54.17 \%$ in controls. And the A and $\mathrm{G}$ allele frequencies were $32.32 \%, 67.68 \%$ in case group, and $29.17 \%, 70.83 \%$ in control group respectively. Data showed that neither genotype nor allele of rs4758994 polymorphism were associated with the risk of AS $(P>0.05)$.

\section{Discussion}

AS, a common autoimmune disease, has a complicated pathogenesis mechanism that is closely related to the body's immune functions[18]. AS is one of the seronegative spondyloarthropathies, which can give rise to varying degrees of complications including eyes, lungs, muscle and bone lesions[19]. The etiology of AS is complex, but a lot of work has confirmed that genetic and environmental factors contribute to its etiology. It has been indicated that $T$ helper cells (Th cells), a type of T cell, play an important role in the regulation of immune response and the balance of Th1/Th2 cells determines the response of the immune system[20]. The preferred treatment of AS is through a multidisciplinary approach that involves exercise, physiotherapy, and drug therapy[21, 22]. It is believed that AS is a polygenic disease caused by the combined influence of environmental and genetic factors. In recent years, it has become the most promising molecular genetics research method to investigate the genetic polymorphisms of candidate genes of AS onset.

TESPA1 gene interacts with Lat signalosome that formed in the TCR signaling, which play a key role in the regulation of T cell development. TESPA 1 is located on human chromosome 12 with $36729 \mathrm{bp}$ in size[23]. Liu S et al.'s work found no association between the four polymorphisms (rs1801876, rs2171497, rs4758994, and rs997173) of the TESPA1 gene and AS in Chinese adults, but may play an important role in the clinical characteristics of AS[24]. However, recent investigations have indicated that the correlation between the allele (G) in rs4758993 and familial RA is relatively significant, suggesting that TESPA1 may play an important role in RA patients[17]. Therefore, in this study we evaluated the link between Tespa1 polymorphisms with the occurrence and disease activity of AS.

In this research, we investigated the effects of TESPA1 rs4758993 and rs4758994 polymorphisms on AS susceptibility. The results showed that rs 4758993 was significantly associated with the individual susceptibility to AS, but independent association was not detected based on genotypes or alleles of rs4758994 for the risk of AS. In single nucleotide polymorphism analysis, the data showed that people with rs4758993 GA genotype showed a significant lower risk to suffer from AS, compared with the AS with GG and AA genotypes. Besides, the major allele (G) inrs4758993 may be a risk allele associated with AS. A allele of rs4758993 had distinctly low frequency in AS patients. It suggested that A allele was 
distinctly correlated with reduced AS risk. Present results were conformed with previous study. A major study has presented that TESPA1 rs4758993 SNP shows significant relationship with RA development in the Zhejiang Han population[17]. In the present study, we examined the association between rs4758994 polymorphism and susceptibility to AS in a Chinese Han population. The allele and genotype frequencies of rs4758994 in patients and healthy controls are shown in Table 2. Although no significant association of rs4758994 with AS susceptibility in this paper, it should be replicated in more other studies to verify the results.

\section{Conclusions}

In conclusion, results from this case-control study revealed that TESPA1 rs4758993 polymorphism, but not rs4758994, significantly decreases the risk of AS in the Chinese Han population. However, many limitations in present study should not be ignored. Further genetic studies of TESPA1 gene polymorphisms in more haplotype blocks and various populations are necessary.

\section{Abbreviations}

thymocyte-expressed, positive selection-associated 1 (TESPA1)

ankylosing spondylitis(AS)

polymerase chain reaction (PCR)

Hardy-Weinberg equilibrium (HWE)

odds ratios (OR)

$95 \%$ confidence intervals $(95 \% \mathrm{Cl})$

spondyloarthropathy (SpA)

protein tyrosine phosphatase non-receptor type 22 (PTPN22)

T cell receptor (TCR)

\section{Declarations}

\section{Ethics approval and consent to participate}

This study was supported by the Ethics Committee of Beijing Tsinghua Changgung Hospital, School of Clinical Medicine, Tsinghua University and also has been carried out in accordance with the World Medical Association Declaration of Helsinki. 
The subjects had been informed the objective. Certainly, written consents were signed by every subject in this study.

\section{Consent for publication}

We obtaining permission from participants to publish their data.

\section{Availability of data and materials}

The datasets used and/or analysed during the current study are available from the corresponding author on reasonable request.

\section{Competing interests}

The authors declare that they have no competing interests.

\section{Funding}

Not applicable.

\section{Authors' contributions}

H.L., D.W., D.H. design of the work; J.D., J.Z., K.X. the acquisition, analysis, D.H., J.L., W.H. interpretation of data; Y.W., S.X. the creation of new software used in the work; L.F., H.L. have drafted the work or substantively revised it. All authors read and approved the final manuscript.

\section{Acknowledgements}

Not applicable.

\section{References}

1. Zhang X, Han R, Wang M, Li X, Yang X, Xia Q, Liu R, Yuan Y, Hu X, Chen M, et al. Association between the autophagy-related gene ULK1 and ankylosing spondylitis susceptibility in the Chinese Han population: a case-control study. Postgraduate medical journal. 2017;93(1106):752-7.

2. Xu H, Li B. Effect of Interferon-gamma Polymorphisms on Ankylosing Spondylitis: A Case-Control Study. Medical science monitor: international medical journal of experimental clinical research. 2017;23:4126-31.

3. Wei JC, Hung KS, Hsu YW, Wong RH, Huang CH, Jan MS, Wu SJ, Juan YS, Chang WC. Genetic polymorphisms of stromal interaction molecule 1 associated with the erythrocyte sedimentation rate and C-reactive protein in HLA-B27 positive ankylosing spondylitis patients. PloS one. 2012;7(12):e49698.

4. Mikuls TR, Levan T, Gould KA, Yu F, Thiele GM, Bynote KK, Conn D, Jonas BL, Callahan LF, Smith E, et al. Impact of interactions of cigarette smoking with NAT2 polymorphisms on rheumatoid arthritis risk 
in African Americans. Arthritis rheumatism. 2012;64(3):655-64.

5. Ho HH, Chen JY. Ankylosing spondylitis: Chinese perspective, clinical phenotypes, and associated extra-articular systemic features. Curr Rheumatol Rep. 2013;15(8):344.

6. Laza IM, Hervella M, C DE-L-R. Genetic Markers in a Medieval Case of Ankylosing Spondylitis. J Rhuematol. 2016;43(3):679-81.

7. Robinson PC, Brown MA. The genetics of ankylosing spondylitis and axial spondyloarthritis. Rheum Dis Clin North Am. 2012;38(3):539-53.

8. Zhang X, Ding W. Association of Genetic Variants in Pentraxin 3 Gene with Ankylosing Spondylitis. Medical science monitor: international medical journal of experimental clinical research. 2016;22:2911-6.

9. Wang W, Meng X, Liu Y, Ma X, Zhang Q, Li C, Ren L: Association Between Protein Tyrosine Phosphatase Non-Receptor Type 22 (PTPN22) Polymorphisms and Risk of Ankylosing Spondylitis: A Meta-analysis. Medical science monitor: international medical journal of experimental and clinical research 2017, 23:2619-2624.

10. Safrany E, Pazar B, Csongei V, Jaromi L, Polgar N, Sipeky C, Horvath IF, Zeher M, Poor G, Melegh B. Variants of the IL23R gene are associated with ankylosing spondylitis but not with Sjogren syndrome in Hungarian population samples. Scand J Immunol. 2009;70(1):68-74.

11. Wang D, Zheng M, Lei L, Ji J, Yao Y, Qiu Y, Ma L, Lou J, Ouyang C, Zhang X, et al. Tespa1 is involved in late thymocyte development through the regulation of TCR-mediated signaling. Nature immunology. 2012;13(6):560-8.

12. Matsuzaki H, Fujimoto T, Ota T, Ogawa M, Tsunoda T, Doi K, Hamabashiri M, Tanaka M, Shirasawa S. Tespa1 is a novel inositol 1,4,5-trisphosphate receptor binding protein in $\mathrm{T}$ and $\mathrm{B}$ lymphocytes. FEBS open bio. 2012;2:255-9.

13. Garcia MI, Karlstaedt A, Chen JJ, Amione-Guerra J, Youker KA, Taegtmeyer H, Boehning D. Functionally redundant control of cardiac hypertrophic signaling by inositol 1,4,5-trisphosphate receptors. J Mol Cell Cardiol. 2017;112:95-103.

14. Chamero P, Weiss J, Alonso MT, Rodriguez-Prados M, Hisatsune C, Mikoshiba K, Leinders-Zufall T, Zufall F. Type 3 inositol 1,4,5-trisphosphate receptor is dispensable for sensory activation of the mammalian vomeronasal organ. Scientific reports. 2017;7(1):10260.

15. Lee DH, Kim HH, Cho HJ, Yu YB, Kang HC, Kim JL, Lee JJ, Park HJ. Cordycepin-Enriched WIB801C from Cordyceps militaris Inhibits Collagen-Induced [Ca(2+)]i Mobilization via cAMP-Dependent Phosphorylation of Inositol 1, 4, 5-Trisphosphate Receptor in Human Platelets. Biomolecules therapeutics. 2014;22(3):223-31.

16. Wang C, Liao Q, Hu Y, Zhong D. T lymphocyte subset imbalances in patients contribute to ankylosing spondylitis. Experimental therapeutic medicine. 2015;9(1):250-6.

17. Yao Y, Zhang H, Shao S, Cui G, Zhang T, Sun H. Tespa1 is associated with susceptibility but not severity of rheumatoid arthritis in the Zhejiang Han population in China. Clin Rheumatol. 2015;34(4):665-71. 
18. Almasi S, Aslani S, Poormoghim H, Jamshidi AR, Poursani S, Mahmoudi M. Gene Expression Profiling of Toll-Like Receptor 4 and 5 in Peripheral Blood Mononuclear Cells in Rheumatic Disorders: Ankylosing Spondylitis and Rheumatoid Arthritis. Iran J Allergy Asthma Immunol. 2016;15(1):87-92.

19. Wang J, Li H, Gao X. Association between ERAP1 gene polymorphisms and ankylosing spondylitis susceptibility in Han population. Int J Clin Exp Pathol. 2015;8(9):11641-6.

20. Wen JT, Zhang DH, Fang PF, Li MH, Wang RJ, Li SH. Role of Th1/Th2 cytokines in the diagnosis and prognostic evaluation of ankylosing spondylitis. Genetics and molecular research: GMR 2017, 16(1).

21. Wendling D. An overview of investigational new drugs for treating ankylosing spondylitis. Expert opinion on investigational drugs. 2016;25(1):95-104.

22. Sari I, Ozturk MA, Akkoc N. Treatment of ankylosing spondylitis. Turkish journal of medical sciences. 2015;45(2):416-30.

23. Gascoigne NR, Fu G. Tespa1: another gatekeeper for positive selection. Nature immunology. 2012;13(6):530-2.

24. Liu S, Liu L, Wu S, Yang T, Pan F, Laslett L, Xia G, Hu Y, Fan D, Ding N, et al: Lack of association between TESPA1 gene polymorphisms (rs1801876, rs2171497, rs4758994, and rs997173) and ankylosing spondylitis in a Chinese population. Inflammation 2014, 37(6):2040-2046.

\section{Tables}

Table 1. Primer sequences of TESPA1 gene two polymorphisms rs4758993 and rs4758994

\begin{tabular}{cccc}
\hline SNP & Primer sequences & Annealing temperature $\left({ }^{\circ} \mathrm{C}\right)$ \\
\hline \multirow{2}{*}{ rs4758993 } & Sense & 5'-GCT GAG GGTAAG AAG TTG C-3' & 56.5 \\
& Reverse & 5'-CGT ATT GGT GGC TGG TAG- 3' & \\
rs4758994 & Sense & 5'-CAGGCTGGAAGGCTCAGGATCT-3' & 57.7 \\
& Reverse & 5'-GACCAAGCTCCTTTGGGCAGAC- 3' & \\
\hline
\end{tabular}

Table 2. Genotype and allele distributions of TESPA1 gene rs4758993 and rs4758994 polymorphisms in case and control groups 


\begin{tabular}{|c|c|c|c|c|c|}
\hline Genotype/ Allele & Case & Control & $\chi^{2}$ & $\mathrm{P}$ & OR(95\% CI) \\
\hline & $n=99(\%)$ & $n=96(\%)$ & & & \\
\hline \multicolumn{6}{|l|}{ rs4758993 } \\
\hline GG & $87(87.88)$ & 66(68.75) & - & - & 1 \\
\hline AG & $12(12.12)$ & $30(31.25)$ & 10.553 & 0.001 & $0.303(0.144-0.637)$ \\
\hline $\mathrm{AA}$ & $0(0)$ & $0(0)$ & - & - & - \\
\hline G & 186(93.93) & 162(84.38) & - & - & 1 \\
\hline A & $12(6.06)$ & $30(15.62)$ & 9.279 & 0.002 & $0.348(0.173-0.703)$ \\
\hline$P_{\mathrm{HWE}}$ & 0.521 & 0.070 & & & \\
\hline \multicolumn{6}{|l|}{ rs4758994 } \\
\hline GG & 13(13.13) & $12(12.5)$ & - & - & 1 \\
\hline GA & 38(38.38) & $32(33.33)$ & 0.039 & 0.844 & $1.096(0.439-2.736)$ \\
\hline $\mathrm{AA}$ & $48(48.49)$ & $52(54.17)$ & 0.128 & 0.720 & $0.852(0.354-2.049)$ \\
\hline G & $64(32.32)$ & $56(29.17)$ & - & - & 1 \\
\hline A & 198(67.68) & $136(70.83)$ & 1.280 & 0.258 & $1.274(0.837-1.939)$ \\
\hline$P_{\mathrm{HWE}}$ & 0.222 & 0.058 & & & \\
\hline
\end{tabular}

